\title{
Relationships between age at first substance use and persistence of cannabis use and cannabis use disorder
}

\author{
Seán R. Millar ${ }^{1,2^{*}}$, Deirdre Mongan ${ }^{1}$, Bobby P. Smyth ${ }^{3}$, Ivan J. Perry ${ }^{2}$ and Brian Galvin ${ }^{1}$
}

\begin{abstract}
Background: From a secondary prevention perspective, it is useful to know who is at greatest risk of progressing from substance initiation to riskier patterns of future use. Therefore, the aim of this study was to determine relationships between age at first use of alcohol, tobacco and cannabis and patterns of cannabis use, frequency of use and whether age of substance use onset is related to having a cannabis use disorder (CUD).

Methods: We analysed data from Ireland's 2010/11 and 2014/15 National Drug Prevalence Surveys, which recruited 5134 and 7005 individuals respectively, aged 15 years and over, living in private households. We included only those people who reported lifetime cannabis use. Multinomial, linear and binary logistic regression analyses were used to determine relationships between age of substance use onset and patterns of cannabis use, frequency of use and having a CUD.
\end{abstract}

Results: When compared to former users, the odds of being a current cannabis user were found to be reduced by $11 \%(\mathrm{OR}=0.89 ; 95 \% \mathrm{Cl}: 0.83,0.95)$ and $4 \%(\mathrm{OR}=0.96 ; 95 \% \mathrm{Cl}: 0.92,1.00)$ for each year of delayed alcohol and cannabis use onset, respectively. Among current users, significant inverse linear relationships were noted, with increasing age of first use of tobacco $(\beta=-0.547 ; P<.001)$ and cannabis $(\beta=-0.634 ; P<.001)$ being associated with a decreased frequency of cannabis use within the last 30 days. The odds of having a CUD were found to be reduced by $14 \%(\mathrm{OR}=0.86 ; 95 \% \mathrm{Cl}: 0.78,0.94)$ and $11 \%(\mathrm{OR}=0.89 ; 95 \% \mathrm{Cl}: 0.82,0.98)$ for each year of delayed tobacco and cannabis use onset respectively in analyses which examined survey participants aged 15-34 years.

Conclusions: Among people who report past cannabis use, it is those with a more precocious pattern of early use of substances, including alcohol, and especially tobacco and cannabis, who are more likely to report ongoing, heavy and problematic cannabis use. Secondary prevention initiatives should prioritise people with a pattern of very early onset substance use.

Keywords: Cannabis, Use, Abuse, Dependence, Age, Onset, Tobacco, Alcohol

\footnotetext{
* Correspondence: smillar@hrb.ie; s.millar@ucc.ie

'Health Research Board, Grattan House 67-72 Lower Mount Street, Dublin, Ireland

${ }^{2}$ School of Public Health, University College Cork, 4th Floor, Western Gateway Building, Cork, Ireland

Full list of author information is available at the end of the article
}

(c) The Author(s). 2021 Open Access This article is licensed under a Creative Commons Attribution 4.0 International License, which permits use, sharing, adaptation, distribution and reproduction in any medium or format, as long as you give appropriate credit to the original author(s) and the source, provide a link to the Creative Commons licence, and indicate if changes were made. The images or other third party material in this article are included in the article's Creative Commons licence, unless indicated otherwise in a credit line to the material. If material is not included in the article's Creative Commons licence and your intended use is not permitted by statutory regulation or exceeds the permitted use, you will need to obtain permission directly from the copyright holder. To view a copy of this licence, visit http://creativecommons.org/licenses/by/4.0/ The Creative Commons Public Domain Dedication waiver (http://creativecommons.org/publicdomain/zero/1.0/) applies to the data made available in this article, unless otherwise stated in a credit line to the data. 


\section{Introduction}

Cannabis is the third most commonly used recreational drug in the world (after alcohol and nicotine) [1]. In the Republic of Ireland, the most recent national survey, conducted in $2014 / 15$, found that $27.9 \%$ of people aged 15-64 years had used cannabis at some point in their lives, with $7.7 \%$ and $4.4 \%$ having used cannabis within the last year or last month respectively [2]. These prevalence figures are considerably higher than those recorded for any other illegal drug and have increased considerably since $2002[3,4]$.

Cannabis use disorder (CUD) is now the most common disorder present in new addiction treatment episodes in the European Union [5]. Across Europe, the number of first-time treatment entrants for primary cannabis use has continuously increased from around 43, 000 (28\% of all new entrants into drug addiction treatment) in 2006 to around 75,000 (47\% of all new treatment entrants) in 2015 [6]. In Ireland, coinciding with an increase in cannabis use, there has also been a substantial increase in treated cannabis addiction and cannabis-related psychiatric problems [7]; among firsttime treatment entrants, cannabis is the most frequently reported main problem drug, accounting for $38 \%$ of all new entrants [8].

There is ongoing debate regarding relationships between early onset substance use and later use of other drugs [9]. The 'common liability model' states that a combination of risk factors places some people at increased risk of both early initiation and of subsequent progression to more serious and sustained drug abuse [10]. Biological, genetic and environmental factors may contribute to risk of early onset of substance use [11]. Neurobiological research has suggested that alcohol, tobacco and other drugs seem to apply to the same neurotransmitters in the brain, proposing a chain of causation between the use of alcohol and cigarettes and subsequent use of cannabis and other drugs [12]. During adolescence there is substantial remodelling of the brain and the endocannabinoid system plays a key role in this process $[11,13]$. Animal and human studies indicate that the brain may be particularly vulnerable to the effects of alcohol, nicotine and cannabis during these adolescent years while the remodelling process is ongoing $[11,14-$ 16]. Lubman et al. have discussed a 'two-hit' model, where individuals who have a combination of biological and environmental risk factors are more likely to use substances during adolescence, and that substance use then causes a neurobiological alteration which further accelerates progression to a substance use disorder [11]. There is also evidence that young people respond differently to cannabis compared to older adults, showing reduced satiety, and this may lead them to use cannabis more heavily [17]. Recent research from the United
States has shown that adolescent onset users of cannabis are more likely to develop a CUD than young adults [18]. It has also been proposed that the link between earlier use of substances and later heavier cannabis use and CUD is symptomatic of people who are at risk of psychosocial disorders [19].

Although numerous studies have examined relationships between early onset drinking, tobacco and cannabis use with later drug use $[9,20]$, this research has tended to focus on a narrow 12-25-year age range. In addition, fewer studies have explored factors associated with progression to ongoing, heavier and problematic cannabis among lifetime cannabis users. It is also unclear whether associations between younger age at substance use onset and cannabis use patterns are independent of other influential factors that may constitute an underlying vulnerability for heavier substance use and substance use disorders [20].

Further research on relationships between age of substance use onset and cannabis is needed. Such knowledge is important to guide future regulation systems, to inform both clinical and public health practice and for assessing drug policy. This is particularly relevant in Ireland at the present time given the increase in number of people being treated for cannabis addiction as well as calls for liberalising cannabis laws [7, 21]. Therefore, the aim of this study was to determine associations between age at first use of alcohol, tobacco and cannabis and cannabis use patterns, drawing on data from two large nationally representative studies which used the same field survey procedures and data collection methods. In particular, we explored how age at first substance use relates to frequency of cannabis use among current users and whether individuals with a CUD are more likely to be earlier users of alcohol, tobacco or cannabis.

\section{Methods \\ Study population and setting}

We analysed data from Ireland's 2010/11 and 2014/15

Drug Prevalence Surveys. These national, cross-sectional studies recruited stratified clustered samples of individuals aged 15 years and over living in private households in Ireland. The numbers interviewed in 2010/11 and 2014/15 were 5134 and 7005, respectively. For both surveys, the sampling frame used was the An Post/Ordnance Survey Ireland GeoDirectory database, which is a list of all addresses in the Republic of Ireland and distinguishes between residential and commercial establishments. A three-stage process was used to construct the sample for each survey. The first stage involved stratifying the population into 10 former health board regions in Ireland. In the second stage of stratification, electoral divisions were selected as the primary sampling units 
across the 10 former health board regions. Before selection, the primary sampling units were ranked by the following sociodemographic indicators: population density, male unemployment and social class, according to the year of data collection, to ensure that a representative cross-section of areas were included. Finally, in each primary sampling unit, addresses were chosen randomly, and at each address, one person was selected to participate in the survey using the 'last birthday' rule. For each survey, the achieved sample was weighted by sex, age and former health board region to maximise its representativeness of the general population. The surveys involved both pre-weights and post-stratification (PS) weights. Pre-weights were used to allow for different selection probabilities of each end respondent, while the PS weights were used to scale up the responses within each demographic cell to represent their respective target populations. A more comprehensive description of the methodology used in the surveys has been detailed elsewhere [22, 23].

The surveys involved face-to-face interviews in the home of each participant and a self-completed questionnaire. The home interviews were conducted by trained interviewers using Computer Assisted Personal Interviewing (CAPI). Fieldwork for the surveys was carried out between October 2010 to May 2011 and August 2014 to August 2015 and both achieved a 60\% response rate. All data collection methods were performed in accordance with relevant guidelines and regulations. No data on non-respondents were collected. The studies were granted ethical approval by the Research Ethics Committee of the Royal College of Physicians in Ireland and signed informed consent was obtained from the parental guardians of minors and from subjects $18+$ years of age for data to be used for research purposes. Ireland's National Drug Prevalence Surveys are GDPR compliant [4].

\section{Measures \\ Outcome variables}

Cannabis use Patterns of cannabis use were defined via the European Monitoring Centre for Drugs and Drug Addiction (EMCDDA) criteria [24]. Respondents who had used cannabis at some point in their lives were classified into one of three mutually exclusive groups. These groups were former users (used cannabis at least once in their life but not in the past year), recent users (used cannabis at least once within the past year but not in the past month) or current users (used cannabis at least once within the past month). Frequency of cannabis use among current users was determined by asking participants: "During the last 30 days on how many days have you taken cannabis?" This was coded as 1-30 days. Data on frequency of use were available for 394 respondents.

Cannabis use disorder (CUD) The Diagnostic and Statistical Manual of Psychiatric Disorders (DSM), better known as the DSM-IV, is published by the American Psychiatric Association and covers all mental health disorders for children and adults. Substance abuse and dependence is defined by the DSM-IV as a maladaptive pattern of substance use leading to clinically significant impairment or distress $[25,26]$. In this study, cannabis abuse and cannabis dependence were classified according to DSM-IV criteria and were measured via a selfcompleted questionnaire using the four items that denote cannabis abuse and seven items that denote cannabis dependence from the Composite International Diagnostic Interview (CIDI). Cannabis abuse was established from a positive response in one or more of the four domains on the DSM-IV diagnostic criteria in the 12 months before the interview. Cannabis dependence was determined from a positive response in three or more of the seven domains on the DSM-IV in the 12 months before the interview. CUD was determined as any cannabis abuse or dependence in the 12 months prior to the interview.

The CIDI is a widely accepted and frequently used operationalisation of the DSM-IV. Advised by the EMCDDA, the abbreviated version, the Munich Composite International Diagnostic Interview (M-CIDI), a 19-item instrument reflecting the four cannabis abuse and the seven cannabis dependence criteria, was used for both the 2010/11 and 2014/15 Drug Prevalence Surveys [27].

\section{Exposure variables}

Age at first use of alcohol, tobacco and cannabis was obtained from questions which asked "At which age did you first try substance $x$ ?" Data on age of first substance use were available for 2901 (alcohol), 2371 (tobacco) and 2956 (cannabis) subjects. Independent variables likely associated with alcohol, tobacco and cannabis use were identified through the literature [4]. Demographic variables selected were sex, age and marital status. Additionally, geographic region (Dublin/outside Dublin) was included to control for any possible effects of sociopolitical and cultural factors present within Ireland. Educational attainment, employment, housing tenure, other lifetime drug use (use of cocaine, ecstasy, amphetamines or sedatives) and current use of alcohol or tobacco were also included as covariates in analyses.

\section{Statistical analysis}

The datasets were codified, affixed with a timestamp variable (year) and merged. Study participants who had 
never used cannabis in their lives were excluded from analyses. Descriptive characteristics were examined according to cannabis use. Displayed frequencies and percentages are weighted. Multinomial logistic regression analyses were used to examine associations between age at first use of alcohol, tobacco and cannabis (as linear variables) and cannabis use patterns. Linear regression was used to test associations between age at first substance use and frequency of cannabis use among subjects who had used cannabis within the last month. Binary logistic regression was used to explore relationships between age at first substance use and CUD (defined as either cannabis abuse or dependence) among subjects who reported using cannabis in the last year. For all regression analyses, an unadjusted model was used to test associations and a second model was adjusted for sex and age. A third model was adjusted for sex, age, marital status, region, education, employment, housing tenure, other lifetime drug use, current alcohol or tobacco use and year of data collection. To examine age-related results, we also compared full sample models to age stratified models in multinomial logistic regression analyses; young adults (aged 15-34 years) vs. older adults (aged 35+ years). These classifications are recommended by the EMCDDA for use in general population surveys [24]. Due to sample size constraints, models which examined age at first substance use with frequency of cannabis use or CUD compared all subjects aged 15 years or over to young adults. There were low levels of missing data. Missing independent variable data were thus assumed to be ignorable and missing at random.

Data analysis was conducted using Stata SE Version 15.1 (Stata Corporation, College Station, TX, USA) for Windows. For all analyses, a P-value (two-tailed) of less than .05 was considered to indicate statistical significance.

\section{Results}

\section{Descriptive characteristics}

Among both surveys there were 2979 (weighted prevalence $=24.6 \%$ ) subjects who indicated having used cannabis at some point in their lives. Characteristics of these subjects according to former, recent and current use, and CUD, are shown in Table 1. The weighted prevalence of former cannabis use was $74.4 \%$ for the combined surveys, while the weighted prevalence of recent and current cannabis use was $12.1 \%$ and $13.5 \%$ of participants, respectively. Among subjects who reported former cannabis use, $53.4 \%$ were aged 35 years or older; $76.8 \%$ and $77.7 \%$ of participants who indicated recent or current use were between 15 and 34 years of age. A higher percentage of survey participants who reported former, recent or current cannabis use were also male.
Within the subset of people who reported recent and current use, 33.1\% reported a CUD defined as either cannabis abuse or dependence. Compared to people who reported former use, participants who indicated recent or current cannabis use, or who had a CUD, were more likely to be single or had never married, had lower educational levels, were less likely to be employed and were more likely to be living in rented accommodation or with family/friends.

Among all subjects, 78 (2.6\%) indicated having never used alcohol; 608 (20.4) had never used tobacco. Among respondents who had used cannabis in the last year, 14 (1.8\%) and 101 (13.2\%) had never used alcohol or tobacco respectively; for subjects who indicated having a CUD, 9 (3.6\%) and 23 (9.1\%) had never tried alcohol or tobacco. Mean age at first substance use was similar between the survey time periods: mean age of first use of alcohol was 16.01 in 2010/11 vs. 15.96 in 2014/15; mean age of first use of tobacco was 15.45 in 2010/11 compared to 15.55 in 2014/15; mean age of first cannabis use was 19.10 in $2010 / 11$ vs. 19.20 in $2014 / 15$. For the combined samples, the mean age of first use of alcohol and cannabis among younger subjects aged 15-34 years was noticeably lower than for participants aged 35 years or older. Among all subjects, mean age at first substance use was also found to be lower among people who reported recent or current use, and among individuals with a CUD, compared to survey participants who reported former cannabis use.

\section{Relationships between age at first substance use and cannabis use patterns}

Table 2 displays odds ratios for the associations between age at first substance use and cannabis use patterns among participants who had used each substance. Among all subjects, the odds of being a current cannabis user (compared to a former user) were found to be reduced by $11 \%(\mathrm{OR}=0.89 ; 95 \%$ CI: $0.83,0.95)$ and $4 \%$ $(\mathrm{OR}=0.96$; 95\% CI: 0.92, 1.00) for each year of delayed alcohol and cannabis use onset, respectively. In stratified models, the relationship between current use and age at first use of cannabis persisted among subjects aged 1534 years $(\mathrm{OR}=0.93 ; 95 \% \mathrm{CI}: 0.86,0.99)$. For survey participants 35 years or older who had used cannabis at some point in their lives, the odds of being a current cannabis user were found to be reduced by $19 \%(\mathrm{OR}=$ 0.81; $95 \%$ CI: $0.73,0.91$ ) for each year of delayed alcohol use onset.

Relationships between age at first substance use and frequency of cannabis use among subjects who had used cannabis in the last month

Linear regression analyses exhibiting associations between age at first substance use and cannabis use 
Table 1 Characteristics of subjects who reported lifetime cannabis use - full sample and according to former, recent and current use and for those with a cannabis use disorder

\begin{tabular}{|c|c|c|c|c|c|}
\hline Variable & $\begin{array}{l}\text { Full } \\
\text { sample } \\
n=2979\end{array}$ & $\begin{array}{l}\text { Former cannabis } \\
\text { use } \\
n=2215\end{array}$ & $\begin{array}{l}\text { Recent cannabis } \\
\text { use } \\
n=362\end{array}$ & $\begin{array}{l}\text { Current cannabis } \\
\text { use } \\
n=402\end{array}$ & $\begin{array}{l}\text { Cannabis use } \\
\text { disorder }^{\text {a }} \\
n=253\end{array}$ \\
\hline \multicolumn{6}{|l|}{ Sex (\%) } \\
\hline Male & $1923(64.4)$ & $1361(61.4)$ & $247(68.2)$ & $316(78.4)$ & $207(81.8)$ \\
\hline \multicolumn{6}{|l|}{ Age group (\%) } \\
\hline $35+$ & $1354(45.5)$ & $1180(53.4)$ & $84(23.2)$ & $90(22.4)$ & $38(15.0)$ \\
\hline $25-34$ & $1102(37.1)$ & $816(36.9)$ & $128(35.4)$ & $159(39.6)$ & $89(35.2)$ \\
\hline $15-24$ & $518(17.4)$ & $215(9.7)$ & $150(41.4)$ & $153(38.1)$ & $126(49.8)$ \\
\hline \multicolumn{6}{|l|}{ Marital status (\%) } \\
\hline Married/cohabiting & $1642(55.2)$ & $1409(63.7)$ & $108(29.9)$ & $125(31.0)$ & $64(25.3)$ \\
\hline Divorced/separated/widowed & $156(5.2)$ & $125(5.7)$ & $11(3.0)$ & $20(5.0)$ & $8(3.2)$ \\
\hline Single/never married & 1178 (39.6) & $678(30.7)$ & $242(67.0)$ & $258(64.0)$ & $181(71.5)$ \\
\hline \multicolumn{6}{|l|}{ Region (\%) } \\
\hline $\begin{array}{l}\text { Dublin (compared to outside } \\
\text { Dublin) }\end{array}$ & $1133(38.0)$ & $819(37.0)$ & $134(37.0)$ & $180(44.7)$ & $101(39.9)$ \\
\hline \multicolumn{6}{|l|}{ Education (\%) } \\
\hline Completed third level & $1677(56.4)$ & $1327(60.0)$ & $179(49.6)$ & $171(42.6)$ & $86(34.3)$ \\
\hline Completed secondary & $998(33.5)$ & $699(31.6)$ & $146(40.4)$ & $152(37.9)$ & $99(39.4)$ \\
\hline Primary/none & $299(10.1)$ & $185(8.4)$ & $36(10.0)$ & $78(19.5)$ & $66(26.3)$ \\
\hline \multicolumn{6}{|l|}{ Employment (\%) } \\
\hline Employed & $1875(63.0)$ & $1517(68.5)$ & $179(49.4)$ & $180(44.7)$ & $101(39.9)$ \\
\hline Unemployed & $527(17.7)$ & $341(15.4)$ & $73(20.2)$ & $113(28.0)$ & $81(32.0)$ \\
\hline Student & $321(10.8)$ & $141(6.4)$ & $97(26.8)$ & $83(20.6)$ & $57(22.5)$ \\
\hline Other & $256(8.6)$ & $215(9.7)$ & $13(3.6)$ & $27(6.7)$ & $14(5.5)$ \\
\hline \multicolumn{6}{|l|}{ Housing tenure (\%) } \\
\hline Owned & $1657(55.6)$ & $1379(62.3)$ & $165(45.5)$ & $113(28.1)$ & $75(29.6)$ \\
\hline Rented & $1033(34.7)$ & $687(31.0)$ & $144(39.7)$ & $203(50.5)$ & $118(46.6)$ \\
\hline Living with family/friends or other & $289(9.7)$ & $149(6.7)$ & $54(14.9)$ & $86(21.4)$ & $60(23.7)$ \\
\hline \multicolumn{6}{|l|}{ Other lifetime drug use (\%) } \\
\hline Yes & $1410(47.3)$ & $938(42.3)$ & $181(50.0)$ & $291(72.2)$ & $187(73.9)$ \\
\hline \multicolumn{6}{|l|}{ Current alcohol use (\%) } \\
\hline Yes & $2452(82.4)$ & $1781(80.4)$ & $324(89.5)$ & $348(86.6)$ & $211(83.1)$ \\
\hline \multicolumn{6}{|l|}{ Current tobacco use (\%) } \\
\hline Yes & $1417(47.6)$ & 867 (39.2) & $226(62.4)$ & $324(80.6)$ & $197(77.9)$ \\
\hline \multicolumn{6}{|l|}{ Age at first use (mean) ${ }^{b}$} \\
\hline \multicolumn{6}{|l|}{ All subjects } \\
\hline Alcohol & $15.98 \pm 2.2$ & $16.19 \pm 2.3$ & $15.59 \pm 1.7$ & $15.20 \pm 1.8$ & $15.15 \pm 1.7$ \\
\hline Tobacco & $15.50 \pm 3.3$ & $15.62 \pm 3.4$ & $15.55 \pm 2.8$ & $14.94 \pm 3.1$ & $14.75 \pm 2.7$ \\
\hline Cannabis & $19.16 \pm 5.0$ & $19.66 \pm 5.2$ & $18.14 \pm 4.0$ & $17.27 \pm 3.6$ & $16.84 \pm 3.4$ \\
\hline \multicolumn{6}{|l|}{ Subjects aged 15-34 years } \\
\hline Alcohol & $15.61 \pm 1.6$ & $15.75 \pm 1.6$ & $15.47 \pm 1.6$ & $15.26 \pm 1.7$ & $15.22 \pm 1.7$ \\
\hline Tobacco & $15.28 \pm 2.6$ & $15.30 \pm 2.7$ & $15.48 \pm 2.6$ & $15.09 \pm 2.4$ & $14.65 \pm 2.5$ \\
\hline Cannabis & $17.74 \pm 2.6$ & $18.07 \pm 2.6$ & $17.48 \pm 2.5$ & $16.85 \pm 2.4$ & $16.52 \pm 2.5$ \\
\hline
\end{tabular}

Subjects aged $35+$ years 
Table 1 Characteristics of subjects who reported lifetime cannabis use - full sample and according to former, recent and current use and for those with a cannabis use disorder (Continued)

\begin{tabular}{clllll}
\hline Variable & $\begin{array}{l}\text { Full } \\
\text { sample } \\
\boldsymbol{n = 2 9 7 9}\end{array}$ & $\begin{array}{l}\text { Former cannabis } \\
\text { use }\end{array}$ & $\begin{array}{l}\text { Recent cannabis } \\
\boldsymbol{n}=\mathbf{2 2 1 5}\end{array}$ & $\begin{array}{l}\text { Current cannabis } \\
\boldsymbol{n}=\mathbf{3 6 2}\end{array}$ & $\begin{array}{l}\text { Cannabis use } \\
\text { use } \\
\text { disorder }^{\mathbf{a}} \\
\boldsymbol{n}=\mathbf{4 0 2}\end{array}$ \\
\hline Alcohol & $16.44 \pm 2.7$ & $16.58 \pm 2.8$ & $15.98 \pm 2.0$ & $14.98 \pm 2.2$ & $14.78 \pm 1.7$ \\
Tobacco & $15.76 \pm 3.9$ & $15.89 \pm 3.8$ & $15.76 \pm 3.4$ & $14.44 \pm 4.9$ & $15.25 \pm 3.5$ \\
Cannabis & $20.85 \pm 6.4$ & $21.06 \pm 6.4$ & $20.28 \pm 6.5$ & $18.68 \pm 6.0$ & $18.59 \pm 6.3$ \\
\hline
\end{tabular}

Displayed frequencies, percentages (in brackets) and means \pm one standard deviation are weighted. Numbers may not add up in column totals because of missing data

${ }^{a}$ Any cannabis abuse or dependence

bData on age of first substance use were available for 2901 (alcohol), 2371 (tobacco) and 2956 (cannabis) subjects

frequency are presented in Table 3. Among all subjects who had used cannabis in the last month, age at first use of tobacco $(\beta=-0.547 ; P<.001)$ and cannabis $(\beta=-$ $0.634 ; P<.001)$ were found to be independently inversely associated with greater frequency of cannabis use within the last 30 days in fully adjusted models. For younger adults aged 15-34 years, age at first use of alcohol, tobacco and cannabis were each found to be significantly inversely associated with frequency of cannabis use in the last month, with relationships for age of tobacco use $(\beta=-1.138 ; \quad P<.001)$ and cannabis use $(\beta=-1.343$; $P<.001)$ onset being noticeably stronger than for alcohol $(\beta=-0.661 ; P=.023)$.

\section{Relationships between age at first substance use and CUD}

Table 4 shows associations between age at first substance use and CUD among respondents who had used cannabis in the last year. Among all subjects in this cohort, no associations were observed between age at first use of alcohol, tobacco or cannabis and CUD in full models. However, the odds of having a CUD were found to be reduced by $14 \%(\mathrm{OR}=0.86 ; 95 \% \mathrm{CI}: 0.78,0.94)$ and $11 \%(\mathrm{OR}=0.89 ; 95 \% \mathrm{CI}$ : $0.82,0.98)$ for each year of delayed tobacco and cannabis use onset respectively in analyses which examined younger survey participants.

\section{Discussion}

In this study we used data from Ireland's 2010/11 and 2014/15 National Drug Prevalence Surveys to determine relationships between age at first use of alcohol, tobacco and cannabis and patterns of cannabis use, frequency of use within the last 30 days and whether age at first substance use was related to having a CUD. For the full sample, when compared to former users, the odds of being a current cannabis user were found to be reduced by $11 \%$ and $4 \%$ for each year of delayed alcohol and cannabis use onset, respectively. Among subjects who indicated current cannabis use, significant inverse linear relationships were noted, with increasing age of first use of tobacco and cannabis being associated with a decreased frequency of cannabis use within the last
30 days. In addition, fully adjusted models demonstrated relationships between age at first use of tobacco and cannabis and having a CUD among subjects aged 15-34 years of age.

Although previous studies on the relationship between alcohol and cannabis are conflicting, our finding that earlier onset of tobacco and cannabis was associated with heavier current cannabis use has been observed in the literature [9, 12, 28, 29]. We also noted that mean age of first use of alcohol and tobacco was lower than cannabis among survey participants. Consequently, these findings could be interpreted as a supporting the sequential initiation pattern of alcohol and tobacco preceding cannabis use. However, although substance use in Western societies normally begins with alcohol or tobacco use, studies have suggested that many other factors also influence patterns of cannabis use, thus limiting the predictive ability of age of onset as a risk factor for later use of the drug [30]. These factors include context of first use, type of use, timing of use, family substance use, parental education, externalising behaviours and conduct problems [31-33].

Nevertheless, the linear associations observed in this study showing that earlier use of tobacco and cannabis was related to heavier cannabis use among current users are important in light of research demonstrating that a dose-response relationship may exist between frequency of cannabis use and adverse health effects [34], including mental health disorders, acute psychotic symptoms, abnormal cognitive development, chronic lung disease and cardiovascular disease [1, 35]. Research has also suggested that earlier onset substance use may lead to assimilation into deviant and substance-using peer groups, which in turn may lead to increased risk of escalation of substance use [36]. Proposals to liberalise cannabis laws are currently being explored in many countries, with some jurisdictions having commenced legalisation of cannabis [37]. In 2019, legislation was passed to allow for a Medical Cannabis Access Programme to come into operation in Ireland on a pilot basis for 5 years. While there has been concern that legalising cannabis for medical or adult use may increase adolescent use [38, 39], 
Table 2 Associations between age at first substance use and cannabis use patterns among subjects who reported lifetime cannabis use - multinomial logistic regression $(n=2979)$

\begin{tabular}{|c|c|c|c|c|c|c|}
\hline \multirow[t]{3}{*}{ Age at first use } & \multicolumn{6}{|c|}{ Cannabis use patterns } \\
\hline & \multicolumn{3}{|c|}{ Recent use vs. former use } & \multicolumn{3}{|c|}{ Current use vs. former use } \\
\hline & OR & $95 \% \mathrm{Cl}$ & $P$-value & OR & $95 \% \mathrm{Cl}$ & $P$-value \\
\hline \multicolumn{7}{|l|}{ All subjects } \\
\hline \multicolumn{7}{|c|}{ Alcohol $(n=2901)$} \\
\hline Model 1 & 0.86 & $0.81,0.91$ & $<.001$ & 0.77 & $0.72,0.81$ & $<.001$ \\
\hline Model 2 & 0.93 & $0.87,0.99$ & .036 & 0.82 & $0.76,0.87$ & $<.001$ \\
\hline Model 3 & 0.95 & $0.89,1.02$ & .164 & 0.89 & $0.83,0.95$ & .001 \\
\hline \multicolumn{7}{|c|}{ Tobacco $(n=2371)$} \\
\hline Model 1 & 0.99 & $0.96,1.03$ & .757 & 0.93 & $0.90,0.97$ & $<.001$ \\
\hline Model 2 & 1.01 & $0.97,1.06$ & .627 & 0.93 & $0.89,0.97$ & .001 \\
\hline Model 3 & 1.02 & $0.98,1.07$ & .286 & 0.97 & $0.92,1.02$ & .19 \\
\hline \multicolumn{7}{|c|}{ Cannabis $(n=2956)$} \\
\hline Model 1 & 0.91 & $0.88,0.94$ & $<.001$ & 0.83 & $0.80,0.86$ & $<.001$ \\
\hline Model 2 & 0.99 & $0.96,1.03$ & .71 & 0.89 & $0.85,0.93$ & $<.001$ \\
\hline Model 3 & 1.01 & $0.97,1.04$ & .75 & 0.96 & $0.92,1.00$ & .036 \\
\hline \multicolumn{7}{|c|}{ Subjects aged 15-34 years } \\
\hline \multicolumn{7}{|c|}{ Alcohol $(n=1584)$} \\
\hline Model 1 & 0.90 & $0.82,0.98$ & .011 & 0.83 & $0.76,0.90$ & $<.001$ \\
\hline Model 2 & 0.96 & $0.88,1.06$ & .434 & 0.87 & $0.80,0.95$ & .002 \\
\hline Model 3 & 1.00 & $0.91,1.10$ & .969 & 0.95 & $0.86,1.04$ & .264 \\
\hline \multicolumn{7}{|c|}{ Tobacco $(n=1289)$} \\
\hline Model 1 & 1.03 & $0.97,1.09$ & .377 & 0.97 & $0.92,1.02$ & .251 \\
\hline Model 2 & 1.05 & $0.98,1.11$ & .157 & 0.97 & $0.92,1.03$ & .333 \\
\hline Model 3 & 1.06 & $0.99,1.14$ & .066 & 0.99 & $0.93,1.06$ & .869 \\
\hline \multicolumn{7}{|c|}{ Cannabis $(n=1608)$} \\
\hline Model 1 & 0.92 & $0.87,0.97$ & .001 & 0.82 & $0.78,0.87$ & $<.001$ \\
\hline Model 2 & 0.99 & $0.94,1.06$ & .844 & 0.87 & $0.82,0.92$ & $<.001$ \\
\hline Model 3 & 1.01 & $0.95,1.08$ & .768 & 0.93 & $0.86,0.99$ & .027 \\
\hline \multicolumn{7}{|c|}{ Subjects aged $35+$ years } \\
\hline \multicolumn{7}{|c|}{ Alcohol $(n=1315)$} \\
\hline Model 1 & 0.90 & $0.81,1.00$ & .039 & 0.73 & $0.66,0.81$ & $<.001$ \\
\hline Model 2 & 0.92 & $0.82,1.02$ & .102 & 0.75 & $0.68,0.83$ & $<.001$ \\
\hline Model 3 & 0.91 & $0.81,1.01$ & .086 & 0.81 & $0.73,0.91$ & $<.001$ \\
\hline \multicolumn{7}{|c|}{ Tobacco $(n=1081)$} \\
\hline Model 1 & 0.99 & $0.93,1.05$ & .784 & 0.89 & $0.83,0.95$ & .001 \\
\hline Model 2 & 1.00 & $0.94,1.06$ & .894 & 0.90 & $0.84,0.96$ & .001 \\
\hline Model 3 & 1.00 & $0.94,1.07$ & .957 & 0.94 & $0.87,1.01$ & .077 \\
\hline \multicolumn{7}{|c|}{ Cannabis $(n=1346)$} \\
\hline Model 1 & 0.98 & $0.94,1.02$ & .287 & 0.90 & $0.86,0.96$ & $<.001$ \\
\hline Model 2 & 0.99 & $0.95,1.03$ & .591 & 0.92 & $0.87,0.97$ & .002 \\
\hline Model 3 & 0.99 & $0.95,1.04$ & .77 & 0.95 & $0.91,1.00$ & .063 \\
\hline
\end{tabular}

Odds ratios (OR) and $95 \%$ confidence intervals $(\mathrm{Cl})$ are shown

Model 1: univariate

Model 2: adjusted for sex and age (continuous)

Model 3: adjusted for sex, age, marital status, region, education, employment, housing tenure, other lifetime drug use, current use of alcohol or tobacco and year of data collection 
Table 3 Associations between age at first substance use and cannabis use frequency among subjects who reported using cannabis in the last month - linear regression $(n=394)$

\begin{tabular}{|c|c|c|c|c|}
\hline \multirow[t]{2}{*}{ Age at first use } & \multicolumn{4}{|c|}{ Cannabis use frequency } \\
\hline & $\bar{\beta}$ & S.E. & $95 \% \mathrm{Cl}$ & $P$-value \\
\hline \multicolumn{5}{|l|}{ All subjects } \\
\hline \multicolumn{5}{|c|}{ Alcohol $(n=386)$} \\
\hline Model 1 & -0.807 & 0.25 & $-1.295,-0.318$ & .001 \\
\hline Model 2 & -0.781 & 0.25 & $-1.269,-0.294$ & .002 \\
\hline Model 3 & -0.452 & 0.24 & $-0.928,0.023$ & .062 \\
\hline \multicolumn{5}{|c|}{ Tobacco $(n=368)$} \\
\hline Model 1 & -0.653 & 0.15 & $-0.946,-0.360$ & $<.001$ \\
\hline Model 2 & -0.674 & 0.15 & $-0.968,-0.379$ & $<.001$ \\
\hline Model 3 & -0.547 & 0.15 & $-0.836,-0.258$ & $<.001$ \\
\hline \multicolumn{5}{|c|}{ Cannabis $(n=390)$} \\
\hline Model 1 & -0.675 & 0.12 & $-0.918,-0.432$ & $<.001$ \\
\hline Model 2 & -0.793 & 0.13 & $-1.042,-0.543$ & $<.001$ \\
\hline Model 3 & -0.634 & 0.12 & $-0.878,-0.390$ & $<.001$ \\
\hline \multicolumn{5}{|c|}{ Subjects aged $15-34$ years } \\
\hline \multicolumn{5}{|c|}{ Alcohol $(n=298)$} \\
\hline Model 1 & -0.962 & 0.29 & $-1.531,-0.393$ & .001 \\
\hline Model 2 & -0.982 & 0.29 & $-1.552,-0.412$ & .001 \\
\hline Model 3 & -0.661 & 0.29 & $-1.228,-0.093$ & .023 \\
\hline \multicolumn{5}{|c|}{ Tobacco $(n=282)$} \\
\hline Model 1 & -1.430 & 0.20 & $-1.829,-1.032$ & $<.001$ \\
\hline Model 2 & -1.458 & 0.21 & $-1.862,-1.054$ & $<.001$ \\
\hline Model 3 & -1.138 & 0.21 & $-1.560,-0.717$ & $<.001$ \\
\hline \multicolumn{5}{|c|}{ Cannabis $(n=302)$} \\
\hline Model 1 & -1.413 & 0.20 & $-1.801,-1.026$ & $<.001$ \\
\hline Model 2 & -1.521 & 0.20 & $-1.912,-1.130$ & $<.001$ \\
\hline Model 3 & -1.343 & 0.21 & $-1.751,-0.935$ & $<.001$ \\
\hline
\end{tabular}

Unstandardized $\beta$ coefficients, standard errors (S.E.) and $95 \%$ confidence intervals $(\mathrm{Cl})$ are shown

Model 1: univariate

Model 2: adjusted for sex and age (continuous)

Model 3: adjusted for sex, age, marital status, region, education, employment, housing tenure, other lifetime drug use, current use of alcohol or tobacco and year of data collection

the early evidence on this is certainly not conclusive [40]. Given our finding that earlier onset use was associated with increased likelihood of progressing to a CUD, the impact of policy changes upon age of cannabis initiation will need to be monitored.

Our results showing that age of cannabis use onset was independently associated with having a CUD is also supported by the literature. In a cross-sectional sample of 8068 participants, Le Strat et al. [41] found that the younger respondents were when they began using cannabis, the greater their likelihood of experiencing a CUD. In a representative sample of 1520 youth aged
14.9-17.4 years, Swift et al. [42] found early use onset of cannabis to be related to the risk of becoming cannabis dependent. Interestingly, we additionally found earlier onset of tobacco use to be associated with having a CUD. This finding contrasts with previous research; in a prospective-longitudinal community study of 3021 subjects, Behrendt et al. [20] observed no direct crosssubstance momentum of younger age at first tobacco use for the risk of developing a CUD.

It should be noted, however, that relationships between tobacco and cannabis use onset and CUD were only observed among younger survey respondents in our sample. Nevertheless, a majority (85.0\%) of subjects in our study who indicated having a CUD were aged between 15 and 34 years and mean age at first use of tobacco and cannabis was lower among younger subjects compared to participants aged 35 years or older. This may partly account for observed findings. However, we also noted that relationships between tobacco and cannabis use onset and frequency of cannabis use were noticeably strong among subjects aged 15-34 years of age. Heavier cannabis use is a known risk factor for having a CUD [43]. Consequently, earlier tobacco and cannabis use may be a contributor to the more intense cannabis use necessary for CUD development [20] and this may be of particular importance among younger adults.

In Ireland, the type of cannabis being used has changed in recent years, from relatively low potency resin ('hash') to higher potency herbal cannabis ('weed') [7, 44]. This trend in use of increasingly potent herbal cannabis has also occurred across Europe [45]. Highpotency cannabis is associated with an increased severity of dependence, especially in young people [46]. The increase in use and move towards higher potency products in Ireland has coincided with a substantial increase in treatment presentations [7]. Drug treatment services have traditionally been funded in the absence of comprehensive, quantitative planning models [47]. However, planning models based on the needs of the population are important for the successful implementation of treatment services and to adequately plan these services requires an understanding of the population in need of treatment [48]. From a secondary prevention perspective, it is also necessary to know who is at greatest risk of progressing from substance initiation to riskier patterns of future use. Finding from this research suggest that in Ireland, younger adult cannabis users who report a more precocious pattern of early use of substances, including alcohol and especially tobacco and cannabis, should be targeted.

\section{Strengths and limitations}

This research has several strengths. This is the first study to examine relationships between age of alcohol, 
Table 4 Associations between age at first substance use and having cannabis use disorder ${ }^{\mathrm{a}}$ among subjects who reported using cannabis in the last year - binary logistic regression $(n=764)$

\begin{tabular}{|c|c|c|c|c|c|c|c|c|}
\hline \multirow[t]{2}{*}{ Age at first use } & \multicolumn{2}{|c|}{ Mean age at first use } & \multicolumn{2}{|l|}{ Model 1} & \multicolumn{2}{|l|}{ Model 2} & \multicolumn{2}{|l|}{ Model 3} \\
\hline & $\begin{array}{l}\text { Cannabis use } \\
\text { disorder }\end{array}$ & $\begin{array}{l}\text { No cannabis use } \\
\text { disorder }\end{array}$ & OR $(95 \% \mathrm{Cl})$ & $\begin{array}{l}P \text { - } \\
\text { value }\end{array}$ & OR $(95 \% \mathrm{Cl})$ & $\begin{array}{l}P \text { - } \\
\text { value }\end{array}$ & OR $(95 \% \mathrm{Cl})$ & $\begin{array}{l}P \text { - } \\
\text { value }\end{array}$ \\
\hline \multicolumn{9}{|l|}{ All subjects } \\
\hline Alcohol $(n=750)$ & $15.15 \pm 1.7$ & $15.50 \pm 1.8$ & $\begin{array}{l}0.89(0.82, \\
0.98)\end{array}$ & .012 & $\begin{array}{l}0.89 \text { ( } 0.81 \\
0.98)\end{array}$ & .018 & $\begin{array}{l}0.95(0.86 \\
1.06)\end{array}$ & .354 \\
\hline $\begin{array}{l}\text { Tobacco }(n= \\
663)\end{array}$ & $14.75 \pm 2.7$ & $15.45 \pm 3.2$ & $\begin{array}{l}0.92(0.86, \\
0.97)\end{array}$ & .004 & $\begin{array}{l}0.89(0.83, \\
0.95)\end{array}$ & $<.001$ & $\begin{array}{l}0.94(0.87 \\
1.01)\end{array}$ & .095 \\
\hline $\begin{array}{l}\text { Cannabis }(n= \\
758)\end{array}$ & $16.84 \pm 3.4$ & $18.10 \pm 3.9$ & $\begin{array}{l}0.90(0.85, \\
0.94)\end{array}$ & $<.001$ & $\begin{array}{l}0.91(0.87 \\
0.96)\end{array}$ & .001 & $\begin{array}{l}0.96(0.90 \\
1.02)\end{array}$ & .14 \\
\hline \multicolumn{9}{|c|}{ Subjects aged $15-34$ years } \\
\hline Alcohol $(n=579)$ & $15.22 \pm 1.7$ & $15.44 \pm 1.7$ & $\begin{array}{l}0.92(0.83, \\
1.02)\end{array}$ & .112 & $\begin{array}{l}0.92(0.83 \\
1.03)\end{array}$ & .142 & $\begin{array}{l}0.99(0.87 \\
1.12)\end{array}$ & .867 \\
\hline $\begin{array}{l}\text { Tobacco }(n= \\
502)\end{array}$ & $14.65 \pm 2.5$ & $15.64 \pm 2.4$ & $\begin{array}{l}0.84(0.78, \\
0.91)\end{array}$ & $<.001$ & $\begin{array}{l}0.82(0.76, \\
0.89)\end{array}$ & $<.001$ & $\begin{array}{l}0.86(0.78, \\
0.94)\end{array}$ & .001 \\
\hline $\begin{array}{l}\text { Cannabis }(n= \\
584)\end{array}$ & $16.52 \pm 2.4$ & $17.52 \pm 2.4$ & $\begin{array}{l}0.84(0.78 \\
0.90)\end{array}$ & $<.001$ & $\begin{array}{l}0.84(0.78 \\
0.91)\end{array}$ & $<.001$ & $\begin{array}{l}0.89(0.82 \\
0.98)\end{array}$ & .012 \\
\hline
\end{tabular}

Odds ratios (OR) and $95 \%$ confidence intervals $(\mathrm{Cl})$ are shown

Model 1: univariate

Model 2: adjusted for sex and age (continuous)

Model 3: adjusted for sex, age, marital status, region, education, employment, housing tenure, other lifetime drug use, current use of alcohol or tobacco and year of data collection

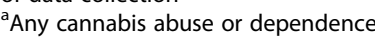

tobacco and cannabis use onset and cannabis use patterns, frequency of cannabis use and CUD, using a sample of lifetime cannabis users from Ireland. A further strength of this research is the large sample size which utilised data from two population studies that used the same field survey procedures and data collection methods and which were weighted and adjusted for the year of data collection; thus, our findings are generalisable to the whole population. We also controlled for important potential confounders in analyses and used valid and reliable measures of cannabis abuse and dependence, defined using the DSM-IV, and Ireland is one of the first countries in Europe to include these variables in two general population surveys. Research on relationships between substance use onset and cannabis use is important for preventative work and for informing and assessing drug policy. This is especially relevant at the present time given the debate regarding the decriminalisation of cannabis in many countries.

Despite these strengths, several limitations should be noted. The cross-sectional study design limits inference with regard to causality and precludes drawing conclusions regarding the temporal direction of relationships. Nevertheless, while a cross-sectional study has reduced ability to identify direction of causality in relationships, it has the advantage of including a much wider age range than typical prospective studies. Another limitation of this research is the use of self-reported questionnaires which are subject to potential inaccuracies, recall and reporting bias. Therefore, residual confounding arising from imprecise measurement of variables should also be considered. Also, we did not have data on other substance use disorders or psychiatric disorders for either survey and these may be important potential confounders. In addition, due to sample size constraints, we analysed cannabis abuse and dependence together rather than as separate constructs. Research examining abuse and dependence separately may be warranted as abuse or dependence criteria may be differentially predictive of adverse outcomes.

\section{Conclusions}

In conclusion, the results from this study of a sample of lifetime cannabis users demonstrate an association between age of alcohol and cannabis use onset and current cannabis use. Subjects who had used tobacco and cannabis at an earlier age were more likely to be heavier users of cannabis. Age of onset of tobacco and cannabis use was significantly related to having a CUD among younger survey respondents. Consequently, these findings suggest that among people who report past cannabis use, it is those with a more precocious pattern of early use of substances, including alcohol and especially tobacco and cannabis, who are more likely to report ongoing, heavy and problematic cannabis use. Prevention initiatives should prioritise people with a pattern of very early onset tobacco or cannabis use. Findings from this study may be used to better inform public health efforts to improve secondary prevention of problematic drug use in the Irish and other populations. 


\section{Abbreviations}

Cl: Confidence Interval; CUD: Cannabis Use Disorder; DSM: Diagnostic and Statistical Manual of Psychiatric Disorders; EMCDDA: European Monitoring Centre for Drugs and Drug Addiction; GDPR: General Data Protection Regulation; M-CIDI: Munich Composite International Diagnostic Interview; OR: Odds Ratio

\section{Acknowledgements \\ Not applicable.}

\section{Authors' contributions}

SRM and DM conceived design of the paper. SRM performed the data analyses and drafted the manuscript. All other authors provided critical revisions. All authors read and approved the final manuscript.

\section{Funding}

Funding for the 2010/11 and 2014/15 Drug Prevalence Surveys was provided by the Department of Health, Ireland. The funder had no role in the analysis, decision to publish or preparation of the manuscript.

\section{Availability of data and materials}

The data used and analysed for the purpose of this study are available from the corresponding author on reasonable request

\section{Declarations}

\section{Ethics approval and consent to participate}

The surveys were granted ethical approval by the Research Ethics Committee of the Royal College of Physicians in Ireland and signed informed consent was obtained from the parental guardians of minors and from subjects $18+$ years of age for data to be used for research purposes. Ireland's National Drug Prevalence Surveys are GDPR compliant.

\section{Consent for publication}

Not applicable.

\section{Competing interests}

No competing interests exist.

\section{Author details}

${ }^{1}$ Health Research Board, Grattan House 67-72 Lower Mount Street, Dublin, Ireland. '2School of Public Health, University College Cork, 4th Floor, Western Gateway Building, Cork, Ireland. ${ }^{3}$ Department of Public Health \& Primary Care, Trinity College Dublin, Russell Building, Tallaght Cross, Dublin, Ireland.

Received: 31 January 2021 Accepted: 6 May 2021

Published online: 27 May 2021

\section{References}

1. World Health Organization. The health and social effects of nonmedical cannabis use. Geneva: World Health Organization; 2016.

2. Health Research Board. Focal Point Ireland: national report for 2017 - drugs. Dublin: Health Research Board; 2018.

3. European Monitoring Centre for Drugs and Drug Addiction. Ireland Country Drug Report 2019. Lisbon: European Monitoring Centre for Drugs and Drug Addiction; 2019

4. Millar SR, Mongan D, O'Dwyer C, Long J, Smyth BP, Perry IJ, et al. Correlates of patterns of cannabis use, abuse and dependence: evidence from two national surveys in Ireland. Eur J Pub Health. 2021;31(2):441-7. https://doi. org/10.1093/eurpub/ckab007.

5. European Monitoring Centre for Drugs and Drug Addiction. Treatment of cannabis-related disorders in Europe. Lisbon: European Monitoring Centre for Drugs and Drug Addiction; 2015.

6. Montanari L, Guarita B, Mounteney J, Zipfel N, Simon R. Cannabis use among people entering drug treatment in Europe: a growing phenomenon? Eur Addict Res. 2017;23(3):113-21. https://doi.org/10.1159/ 000475810.

7. Smyth BP, O'Farrell A, Daly A. Cannabis use and associated health problems-What's the harm? Ir Med J. 2019;12(9):1000.
8. O'Neill D, Carew AM, Lyons S. National Drug Treatment Reporting System 2013-2019 drug data. Dublin: Health Research Board. Available: https:// www.drugsandalcohol.ie/32094/; 2020.

9. Smyth B, Hannigan A, Cullen W. Cocaine use in young adults: correlation with early onset cannabis, alcohol and tobacco use. Ir Med J. 2016;9:468.

10. Van Leeuwen AP, Verhulst FC, Reijneveld SA, Vollebergh WA, Ormel J, Huizink AC. Can the gateway hypothesis, the common liability model and/ or, the route of administration model predict initiation of cannabis use during adolescence? A survival analysis—the TRAILS study. J Adolesc Health. 2011;48(1):73-8. https://doi.org/10.1016/j.jadohealth.2010.05.008.

11. Lubman DI, Cheetham A, Yücel M. Cannabis and adolescent brain development. Pharmacol Ther. 2015;148:1-16. https://doi.org/10.1016/j.pha rmthera.2014.11.009.

12. Baumeister S, Tossmann P. Association between early onset of cigarette alcohol and cannabis use and later drug use patterns: an analysis of a survey in European metropolises. Eur Addict Res. 2005;11(2):92-8. https:// doi.org/10.1159/000083038.

13. Casey B, Jones RM. Neurobiology of the adolescent brain and behavior: implications for substance use disorders. J Am Acad Child Adolesc Psychiatry. 2010;49(12):1189-201. https://doi.org/10.1016/j.jaac.2010.08.017.

14. Orr C, Spechler P, Cao Z, Albaugh M, Chaarani B, Mackey S, et al. Grey matter volume differences associated with extremely low levels of cannabis use in adolescence. J Neurosci. 2019;39(10):1817-27. https://doi.org/10.1523/ INEUROSCI.3375-17.2018.

15. Ren M, Lotfipour S. Nicotine gateway effects on adolescent substance use. Western J Emerg Med. 2019;20(5):696-709. https://doi.org/10.5811/ westjem.2019.7.41661.

16. Spear LP. Effects of adolescent alcohol consumption on the brain and behaviour. Nat Rev Neurosci. 2018;19(4):197-214. https://doi.org/10.1038/ nrn.2018.10

17. Mokrysz C, Freeman TP, Korkki S, Griffiths K, Curran HV. Are adolescents more vulnerable to the harmful effects of cannabis than adults? A placebocontrolled study in human males. Transl Psychiatry. 2016;6(11):e961. https:// doi.org/10.1038/tp.2016.225.

18. Volkow ND, Han B, Einstein EB, Compton WM. Prevalence of substance use disorders by time since first substance use among young people in the US. JAMA Pediatr. 2021.https://doi.org/10.1001/jamapediatrics.2020.6981.

19. Donovan JE, Jessor R. Structure of problem behavior in adolescence and young adulthood. J Consult Clin Psychol. 1985;53(6):890-904. https://doi. org/10.1037/0022-006X.53.6.890.

20. Behrendt S, Beesdo-Baum K, Höfler M, Perkonigg A, Bühringer G, Lieb R, et al. The relevance of age at first alcohol and nicotine use for initiation of cannabis use and progression to cannabis use disorders. Drug Alcohol Depend. 2012; 123(1-3):48-56. https://doi.org/10.1016/j.drugalcdep.2011.10.013.

21. Citywide. The Drugs Crisis in Ireland: a new agenda for action. Dublin: Citywide; 2010.

22. National Advisory Committee on Drugs and Alcohol. General population survey on drug prevalence in Ireland 2010/11. Dublin: Technical report; 2012

23. National Advisory Committee on Drugs and Alcohol. General population survey on drug prevalence in Ireland 2014/15. Dublin: Technical report; 2016

24. European Monitoring Centre for Drugs and Drug Addiction. Methods and Definitions. Lisbon; 2007

25. Samet S, Waxman R, Hatzenbuehler M, Hasin DS. Assessing addiction: concepts and instruments. Addict Sci Clin Pract. 2007;4(1):19-31. https://doi. org/10.1151/ascp074119.

26. Kessler RC, Üstün TB. The world mental health (WMH) survey initiative version of the world health organization $(\mathrm{WHO})$ composite international diagnostic interview (CIDI). Int J Methods Psychiatr Res. 2004;13(2):93-121. https://doi.org/10.1002/mpr.168.

27. Lachner G, Wittchen H-U, Perkonigg A, Holly A, Schuster P, Wunderlich U, et al. Structure, content and reliability of the Munich-composite international diagnostic interview (M-CIDI) substance use sections. Eur Addict Res. 1998;4(1-2):28-41. https://doi.org/10.1159/000018922.

28. Nelson SE, Van Ryzin MJ, Dishion TJ. Alcohol, marijuana, and tobacco use trajectories from age 12 to 24 years: demographic correlates and young adult substance use problems. Dev Psychopathol. 2015;27(1):253-77. https:// doi.org/10.1017/S0954579414000650.

29. Silins E, Hutchinson D, Swift W, Slade T, Toson B, Rodgers B. Factors associated with variability and stability of cannabis use in young adulthood. Drug Alcohol Depend. 2013;133(2):452-8. https://doi.org/10.1016/j.druga Icdep.2013.07.003 
30. Strunin L, Díaz-Martínez A, Díaz-Martínez LR, Heeren T, Chen C, Winter M, et al. Age of onset, current use of alcohol, tobacco or marijuana and current polysubstance use among male and female Mexican students. Alcohol Alcohol. 2017;52(5):564-71. https://doi.org/10.1093/alcalc/agx027.

31. King KM, Chassin L. A prospective study of the effects of age of initiation of alcohol and drug use on young adult substance dependence. J Stud Alcohol Drugs. 2007;68(2):256-65. https://doi.org/10.15288/jsad.2007.68.256.

32. Stone AL, Becker LG, Huber AM, Catalano RF. Review of risk and protective factors of substance use and problem use in emerging adulthood. Addict Behav. 2012;37(7):747-75. https://doi.org/10.1016/j.addbeh.2012.02.014.

33. Johnston LD, O'Malley PM, Bachman JG, Schulenberg JE, Miech RA. Monitoring the future national survey results on drug use, 1975-2013: volume I, secondary school students. Ann Arbor: Institute for Social Research, University of Michigan; 2014.

34. Hall W, Degenhardt L. Adverse health effects of non-medical cannabis use Lancet. 2009;374(9698):1383-91. https://doi.org/10.1016/S0140-6736(09)6103 7-0.

35. Bonner WA, Andkhoie M, Thompson C, Farag M, Szafron M. Patterns and factors of problematic marijuana use in the Canadian population: evidence from three cross-sectional surveys. Can J Public Health. 2017;108(2):e110-6. https://doi.org/10.17269/CJPH.108.5926.

36. Van Ryzin MJ, Dishion TJ. Adolescent deviant peer clustering as an amplifying mechanism underlying the progression from early substance use to late adolescent dependence. J Child Psychol Psychiatry. 2014;55(10): 1153-61. https://doi.org/10.1111/jcpp.12211

37. Cullen P, Bray J. Proposals to liberalise cannabis laws expected before cabinet. Dublin: The Irish Times; 2019.

38. Budney AJ, Borodovsky JT. The potential impact of cannabis legalization on the development of cannabis use disorders. Prev Med. 2017;104:31-6. https://doi.org/10.1016/j.ypmed.2017.06.034.

39. Wilkinson ST, D'Souza DC. Problems with the medicalization of marijuana. JAMA. 2014;311(23):2377-8. https://doi.org/10.1001/jama.2014.6175.

40. Coley RL, Kruzik C, Ghiani M, Carey N, Hawkins SS, Baum CF. Recreational marijuana legalization and adolescent use of marijuana, tobacco, and alcohol. J Adolesc Health. 2020. https://doi.org/10.1016/j.jadohealth.2020.10. 019 .

41. Le Strat $Y$, Dubertret $C$, Le Foll B. Impact of age at onset of cannabis use on cannabis dependence and driving under the influence in the United States. Accid Anal Prev. 2015;76:1-5. https://doi.org/10.1016/..aap.2014.12.015.

42. Swift W, Coffey C, Carlin JB, Degenhardt L, Patton GC. Adolescent cannabis users at 24 years: trajectories to regular weekly use and dependence in young adulthood. Addiction. 2008;103(8):1361-70. https://doi.org/10.1111/ j.1360-0443.2008.02246.x.

43. National Academies of Sciences E, Medicine. The health effects of cannabis and cannabinoids: The current state of evidence and recommendations for research: National Academies Press; 2017.

44. Arnold C. The potency of THC in Cannabis products. Dublin: National Advisory Committee on Drugs; 2011.

45. European Monitoring Centre for Drugs and Drug Addiction. Developments in the European cannabis market, EMCDDA Papers. Luxembourg: Publications Office of the European Union; 2019.

46. Freeman T, Winstock A. Examining the profile of high-potency cannabis and its association with severity of cannabis dependence. Psychol Med. 2015; 45(15):3181-9. https://doi.org/10.1017/S0033291715001178.

47. Rush B, Urbanoski K. Seven Core principles of substance use treatment system design to aid in identifying strengths, gaps, and required enhancements. J Stud Alcohol Drugs. 2019;(s18):9-21.

48. Babor TF, Rush B, Tremblay J. Needs-based planning for substance use treatment systems: progress, prospects, and the search for a new perspective. J Stud Alcohol Drugs. 2019;(s18):154-60.

\section{Publisher's Note}

Springer Nature remains neutral with regard to jurisdictional claims in published maps and institutional affiliations.

Ready to submit your research? Choose BMC and benefit from:

- fast, convenient online submission

- thorough peer review by experienced researchers in your field

- rapid publication on acceptance

- support for research data, including large and complex data types

- gold Open Access which fosters wider collaboration and increased citations

- maximum visibility for your research: over $100 \mathrm{M}$ website views per year

At $\mathrm{BMC}$, research is always in progress.

Learn more biomedcentral.com/submissions 